\title{
Polyol Synthesis of Silver Nanoparticles and Deposition on Carbon Vulcan for 4-Nitrophenol Reduction Catalysis
}

\section{VINH TIEN NGUYEN ${ }^{2}$, QUOC KHANH TRAN ${ }^{1}$ and CANH MINH THANG NGUYEN ${ }^{1,3 *}$}

\author{
${ }^{1}$ Faculty of Chemistry, Ho Chi Minh City University of Science, Vietnam. \\ ${ }^{2}$ Faculty of Food and Chemical Technology, Ho Chi Minh City University of Technology and Education, Vietnam. \\ ${ }^{3}$ Laboratory of Applied Physical Chemistry, Vietnam National University, Ho Chi Minh City, Vietnam. \\ ${ }^{*}$ Corresponding author E-mail: ncmthang @ hcmus.edu.vn
}

http://dx.doi.org/10.13005/ojc/360119

(Received: January 16, 2020; Accepted: February 17, 2020)

\begin{abstract}
Silver nanoparticles (AgNP) were synthesized and then immobilized onto Carbon Vulcan support to be used as a catalyst (AgNP/C) for 4-nitrophenol (4-NP) reduction. Polyol method was used for AgNP synthesis with glycerol-water as the solvent mixture, trisodium citrate (TSC) as the reducing agent and the capping agent, silver nitrate as the silver precursor. The optimized reaction conditions were glycerol content of $35 \%(\mathrm{w} / \mathrm{w})$, temperature of $105^{\circ} \mathrm{C}$, reaction time of $120 \mathrm{~min}$, $\mathrm{TSC} / \mathrm{Ag}^{+}$ratio $(\mathrm{w} / \mathrm{w})$ of 6 . XRD spectrum confirmed the presence of silver nanocrystallites on the prepared catalyst and TEM images their sizes mostly lower than $150 \mathrm{~nm}$. The $\mathrm{Ag} / \mathrm{C}$ catalyst prepared in a mildly basic solution ( $\mathrm{pH}$ 9) showed higher catalytic activity, as well as higher reusability, compared to that prepared in a mildly acidic solution $(\mathrm{pH} \mathrm{5-7).}$
\end{abstract}

Keywords: Silver nanoparticles, Carbon Vulcan, 4-nitrophenol reduction, Polyol method, Immobilization.

\section{INTRODUCTION}

Nitroaromatic compounds, such as nitrobenzenes and nitrophenols, are abundant and chemically stable organic pollutants in agriculture and in the industry ${ }^{1}$. Among different strategies for the disposal of nitroaromatic compounds, reducing the nitro group to an amino group is advantageous due to its high effectiveness and the importance of the reductive products in pharmaceutical and synthetic chemistry². Metallic nanoparticles, such as gold, silver, copper nanoparticles, have emerged as novel effective catalysts for the reduction of nitroaromatic to amino aromatic compounds ${ }^{3}$. However, due to their small sizes, catalyst removal or recovery from the reaction mixture is one of the major challenges toward green chemical processes. A series of silver nanoparticle (AgNP) catalysts supported on activated carbon ${ }^{4-6}, \mathrm{TiO}_{2}{ }^{7}$, silica ${ }^{8,9}$, cellulose ${ }^{10,11}$, zeolites $^{12}$, polymers ${ }^{13-15}$ were synthesized and used for catalytic applications.

Carbon blacks are extensively used as an electrocatalyst support due to their high

This is an Open Access article licensed under a Creative Commons license: Attribution 4.0 International (CC- BY). Published by Oriental Scientific Publishing Company @ 2018 
mesoporous structure, high electrical conductivity, low cost and high availability ${ }^{16}$. Different types of carbon blacks, such as acetylene black, Black Pearl, Ketjen Black, or Vulcan XC-72, have been used as electrodes in supercapacitors or catalyst supports in electrochemical applications. Among them, Vulcan XC 72R, which is industrially manufactured by Cabot Corporation, has attracted special attention due to its compromise between adequate surface area and high electric conductivity. It has been used as a support for noble-metal catalysts in low-temperature fuel cells ${ }^{17}$. However, few studies focus on using Carbon Vulcan as a support in non-electrochemical catalysis ${ }^{18,19}$.

In this study, we synthesized silver nanoparticles by a polyol method without using any hazardous chemicals and then immobilized these AgNP onto activated Carbon Vulcan. The obtained material was successfully used for the first time as a catalyst for the reduction of 4-nitrophenol as a model reduction.

\section{MATERIAL AND METHOD}

\section{Material}

All chemicals were of analytical grade and used without further purification. Sodium borohydride, sodium hydroxide were purchased from Merck Millipore (USA), silver nitrate, glycerol, nitric acid, 4-nitrophenol from Xilong (China), trisodium citrate dihydrate from Prolabo (France), Carbon Vulcan XC72R from Cabot (Germany).

\section{Polyol synthesis of AgNP}

Typically, predetermined amounts of glycerol, $\mathrm{AgNO}_{3}(1000 \mathrm{ppm})$ solution and TSC solutions (1900 ppm) were added to a glass vial containing $6.0 \mathrm{~g}$ of distilled water. The mixture was thoroughly stirred and heated to $95^{\circ} \mathrm{C}$ and kept for 120 minutes. The reaction kinetics was monitored by recording the absorption of the reaction mixture by a UV/VIS/NIR-V670 (JASCO, Japan) spectrophotometer from 300 to $800 \mathrm{~nm}$ with a scan speed of $400 \mathrm{~nm} / \mathrm{min}$ and a data interval of $0.5 \mathrm{~nm}$.

\section{AgNP synthesis and in situ deposition on Carbon Vulcan}

Carbon Vulcan was activated by refluxing $0.25 \mathrm{~g}$ of Carbon Vulcan in $250 \mathrm{~mL}$ of $7 \% \mathrm{HNO}_{3}$ solution for 8 hours. The solid was obtained by centrifugation at $4000 \mathrm{rpm}$ for $15 \mathrm{~min}$, washed three times with distilled water and dried at $110^{\circ} \mathrm{C}$ for 2 hours.
After that, $0.1 \mathrm{~g}$ of pretreated Carbon Vulcan was ultrasonicated in $12 \mathrm{~g}$ of distilled water for 30 minutes. Subsequently, $18 \mathrm{~g}$ of glycerol was added and ultrasonicated for 30 minutes. While continuously stirred, $2.5 \mathrm{~g}$ of $\mathrm{AgNO}_{3}$ solution (10 000 $\mathrm{ppm}$ ) and $7.5 \mathrm{~g}$ of TSC solution (20 $000 \mathrm{ppm}$ ) were successively added. $\mathrm{pH}$ of the mixture was controlled using a pH meter and $\mathrm{NaOH}\left(1.46 \mathrm{M}\right.$ ) or $\mathrm{HNO}_{3}(7 \%)$ solutions. The mixture was then refluxed at $105^{\circ} \mathrm{C}$ for $2 \mathrm{~h}$ centrifuge at $6000 \mathrm{rpm}$ for 30 minutes. The obtained solid Ag/C was then washed for two times with distilled water, one time with absolute ethanol and then dried at $60^{\circ} \mathrm{C}$ for 2 hours.

\section{Kinetic study of catalytic reduction of 4-NP by $\mathrm{NaBH}_{4}$ \\ $2.5 \mathrm{mg}$ of $\mathrm{Ag} / \mathrm{C}$ catalyst was added to} $6.25 \mathrm{~g}$ of distilled water in a vial. The mixture was suspended in a sonication bath for 5 minutes. 0.1 $\mathrm{mL}$ of the suspension was transfered to another vial with $9.2 \mathrm{~g}$ of water. Subsequently, $0.1 \mathrm{~mL}$ of $0.05 \mathrm{M} \mathrm{NaHCO}_{3}$ and $0.1 \mathrm{~mL}$ of $5 \mathrm{mM} \mathrm{4-NP}$ were added. After ultrasonication, $0.5 \mathrm{~mL}$ of 0.1 $\mathrm{M} \mathrm{NaBH}_{4}$ was added and shaken thoroughly. The reaction kinetics was followed by recording the absorbance of the suspension at $400 \mathrm{~nm}$ over time. All experiments were repeated at room temperature $\left(27^{\circ} \mathrm{C}\right)$ for 3 times. In all kinetic experiments, the initial concentration of $\mathrm{NaBH}_{4}$ was 100 times higher than that of 4-NP concentration. Therefore, $\mathrm{NaBH}_{4}$ concentration was considered unchanged and did not affect the reaction rate during the reaction.

\section{RESULTS AND DISCUSSION}

\section{Polyol synthesis of AgNP in solution}

During heating the $\mathrm{AgNO}_{3}$ solution with glycerol, the solution turned from colorless to pale-yellow with maximum absorbance ranging from 408 to $416 \mathrm{~nm}$ due to the surface plasmon resonance (SPR) of silver nanoparticles ${ }^{20}$. In order to optimize the synthesis conditions, the effects of glycerol concentration, reaction time, temperature, TSC concentration were investigated. Many studies proved that higher values of SPR absorbance of the solution correspond to a higher concentration of AgNP. Therefore, we used the maximum absorbance of the solution at SRP wavelengths (around $410 \mathrm{~nm}$ ) as the criteria for the optimum condition ${ }^{21}$. Preliminary experiments showed that the synthesis of AgNP 
still went on after $30 \mathrm{~min}$ and only stopped after 120 minutes. Therefore, 30 min were chosen as the reaction time when optimizing the other factors.

\section{Influence of glycerol concentration}

In polyol synthesis of metallic nanoparticles, the polyol can play the role of a cosolvent, a reducing agent, or/and a capping agent ${ }^{22}$. Therefore, its amount in the reaction medium plays an important role. Preliminary result (Fig. 1a) showed that raising the glycerol content up to $45 \%$ increased the amount of AgNP. However, when moving from $30 \%$ glycerol (absorbance $=1.37$ ) to $45 \%$ glycerol (absorbance $=$ 1.77), the increase of absorbance was relatively small. Moreover, high content of glycerol would increase the viscosity of the solution, which may negatively affect the deposition process of AgNP onto Carbon Vulcan. We decided not to test higher concentrations of glycerol, but to investigate more closely its range from $25 \%$ to $40 \%$ (Fig. 1b). The results showed that $35 \%$ of glycerol produced the highest amount of AgNP, and thus was chosen as the optimum glycerol concentration for AgNP/C synthesis.
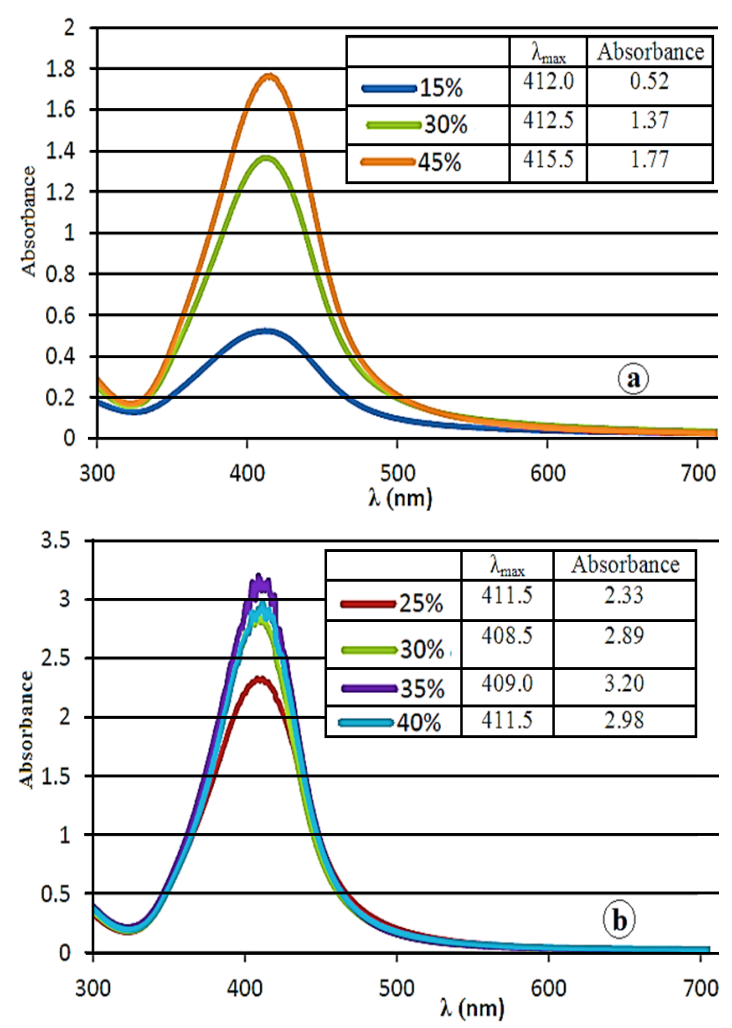

Fig. 1. Influence of glycerol concentration on absorption spectrum of reaction medium. Reaction conditions: $20 \mathrm{ppm}$ $\mathrm{Ag}^{+} ; 200 \mathrm{ppm} \mathrm{TSC}, \mathrm{T}=\mathbf{8 5}^{\circ} \mathrm{C}$, time $=\mathbf{3 0} \mathrm{min}$
Influence of temperature

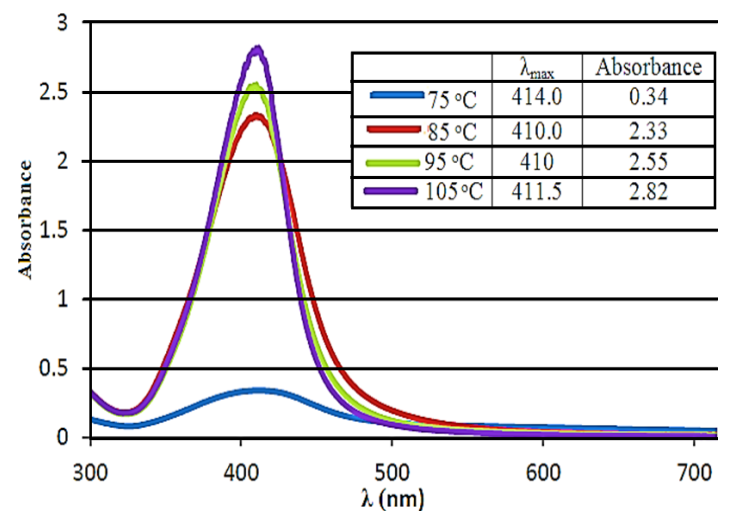

Fig. 2. Influence of reaction temperature on the absorption spectrum of the reaction medium. Reaction conditions: 20 ppm Ag ; 200 ppm TSC, 30\% glycerol, time = 30 minute

Temperature is one of the most important factors for any chemical reaction. Fig. 2 shows that at $75^{\circ} \mathrm{C}$, the reaction extent was limited. However, increasing the reaction temperature up to $105^{\circ} \mathrm{C}$ produced substantially more AgNP. Obviously, at $30 \mathrm{~min}$ the polyol reaction still took place, so increasing the temperature would speed up the reaction and produce higher amount of AgNP. Further increase the temperature would make the solution boil, which requires a more complex synthetic system with a condenser to control the concentrations of the reaction components. Therefore, in the investigated range of reaction temperatures, $105^{\circ} \mathrm{C}$ was chosen as the appropriate temperature for AgNP/C synthesis.

\section{Influence of TSC concentration}

It is well known that TSC plays the dual role of a reducing agent and a capping agent during the polyol synthesis of AgNP22. When TSC was not added to the reaction mixture, the characteristic peak of AgNP at around $410 \mathrm{~nm}$ did not appear. This fact demonstrated the crucial role of TSC in AgNP formation. When the TSC concentration was $40 \mathrm{ppm}$ (2 times of $\left[\mathrm{Ag}^{+}\right]$), AgNP began to form, but at a low extent. When the TSC concentration was 120 ppm (6 times of $\left[\mathrm{Ag}^{+}\right]$) and higher, AgNP concentration almost reached a maximum. Therefore, TSC concentration of six times that of silver ions was chosen as optimized value for AgNP/C catalyst. 


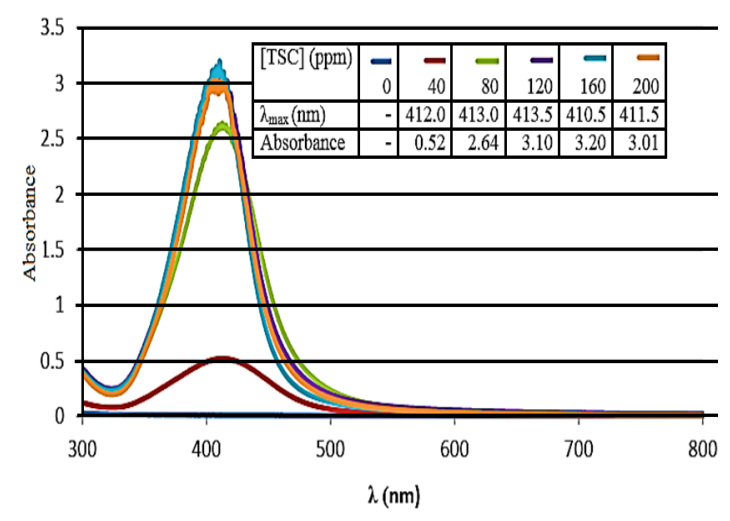

Fig. 3. Influence of TSC concentration on absorption spectrum of reaction medium. Reaction conditions: $20 \mathrm{ppm} \mathrm{Ag} ; 30 \%$ glycerol, $\mathrm{T}=95^{\circ} \mathrm{C} ;$ time $=30$ minute

\section{Characterization of AgNP/C}

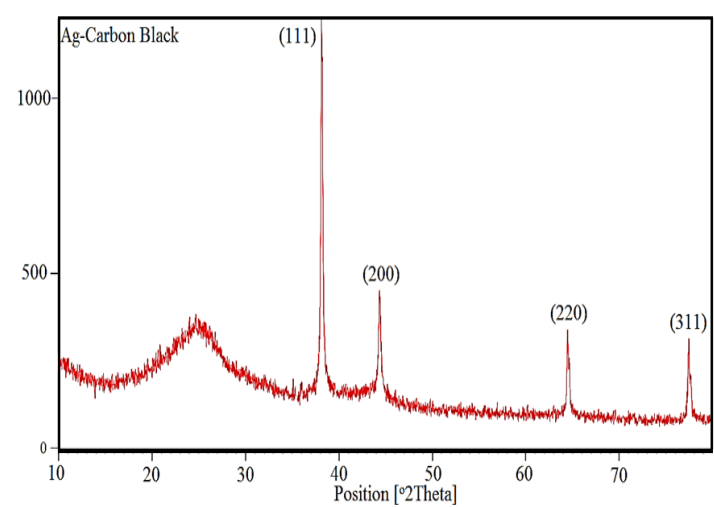

Fig. 4. XRD pattern of the prepared AgNP/C catalyst with assigned silver peaks

XRD spectrum of a synthesized AgNP/C sample (Fig. 4) was compared with the standard spectrum of the face-centered cubic (fcc) structure of bulk silver (JCPDS file No. 04-0783). The spectrum shows four characteristic peaks of metallic silver at $2 \theta$ values of $38.2^{\circ}(111), 44.3^{\circ}(200), 64.5^{\circ}(220)$ and $77.5^{\circ}(311)$, what clearly shows that the as-prepared material contained ffc crystallite silver together with the mostly amorphous Carbon Vulcan. Based on the Scherrer equation, the mean size of the silver crystallites was of ca. $30 \mathrm{~nm}$.

Analysis of TEM images of the AgNP/C prepared in different $\mathrm{pH}$ showed that $\mathrm{AgNP}(\mathrm{Z}=48)$ particles appeared as black figures, while the Carbon Vulcan $(Z=6)$ support as grey clusters. About $90 \%$ of the AgNP had sizes lower than $150 \mathrm{~nm}$, with a mean value of about $70 \mathrm{~nm}$. This value is at the same order with the mean crystallite size obtained by the XRD spectrum above and the Scherrer equation.
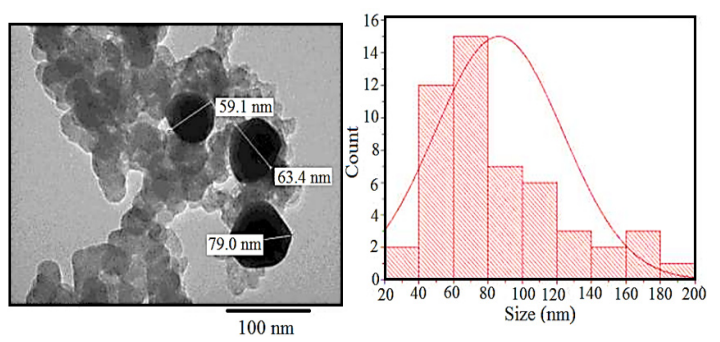

Fig. 5. TEM image of the prepared AgNP/C material (left) and frequency chart of AgNP sizes (right)

\section{Catalytic activity on 4-NP reduction}

Figure 6 shows the change of absorbance $(\lambda=400 \mathrm{~nm})$ of 4-nitrophenolate ions in the solution after adding a constant amount $(2.5 \mathrm{mg})$ of the synthesized AgNP/C catalyst. After an initial induction period due to the reduction of dissolved oxygen by $\mathrm{NaBH}_{4}{ }_{4}^{23}$, the absorbance of 4-NP decreased for 200-300 seconds. Because $\mathrm{NaBH}_{4}$ is in great excess in the reaction, its concentration can be considered constant throughout the reaction. Therefore, pseudo-first-order kinetics can be applied with respect to the concentration of 4-NP3 .

The time periods corresponding to from $60 \%$ to $40 \%$ of initial absorbance $A_{0}$ were chosen for calculation of the apparent rate constants. This choice of intermediate time periods was based on the assumption that, in the proximity of the beginning $\left(A>60 \% A_{0}\right)$ or the end $\left(A<40 \% A_{0}\right)$ of the reaction, the overall reaction kinetics is more heavily influenced by the diffusion of reactants/products to/from the catalyst surface. The apparent rate constants show that AgNP/C catalysts prepared under basic conditions had higher catalytic activity than those prepared under acidic conditions.

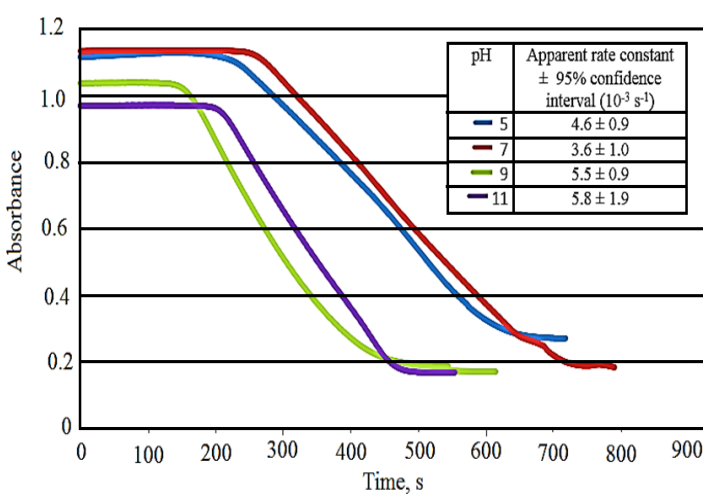

Fig. 6. Kinetics of 4-NP reduction with excess $\mathrm{NaBH}_{4}$ and catalyst AgNP/C

The reusability of the prepared AgNP/C catalyst was evaluated by adding more 4-NP into the reaction mixture every time the reaction has 
stopped. After each cycle of usage, the catalytic activity of all prepared catalysts samples decreased, as demonstrated by the increase of reaction halflives (Fig. 7). This is possibly due to the adsorption of reaction products onto the AgNP surface over time, which reduced the free active centers of the catalyst. Moreover, from the slope of the half-life vs reaction cycle, we can compare the stability of the prepared catalysts toward reuse. It can be seen that the AgNP/C catalyst prepared at mildly alkaline medium

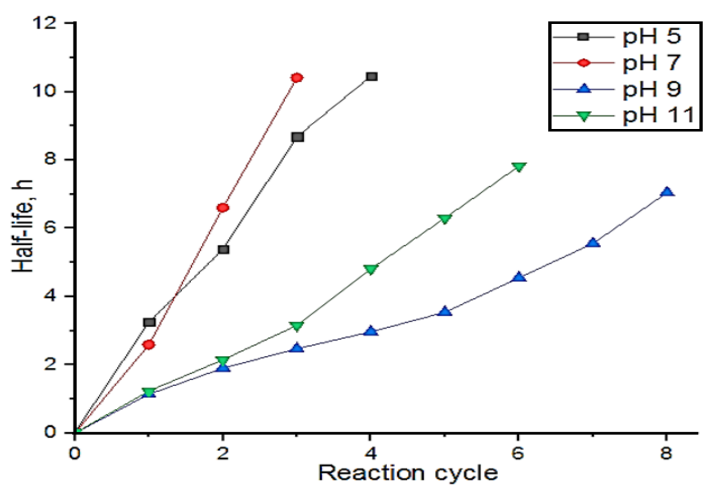

Fig. 7. Increase of reaction half-life with the number of reaction cycles
( $\mathrm{pH} 9)$ was the most stable, while that prepared in acidic $(\mathrm{pH} 5)$ and neutral medium $(\mathrm{pH} 7)$.

\section{CONCLUSION}

In this study, AgNP were synthesized by polyol method and then immobilized onto Carbon Vulcan support to be used as a catalyst for 4-NP reduction. The optimum conditions for AgNP synthesis suspension were determined and applied to prepare AgNP/C catalyst. AgNP/C catalysts prepared in mildly basic solutions showed higher catalytic activity, as well as higher reusability, compared to those prepared in mildly acidic solutions.

\section{ACKNOWLEDGEMENT}

The authors sincerely acknowledge Ho Chi Minh City University of Technology and Education for the financial support and Vietnam National University, Ho Chi Minh City University of Science for the laboratory and equipment supports to complete this study.

\section{Conflicts of interest}

The authors declare no conflict of interest.

\section{REFERENCES}

1. Tiwari, J.; Tarale, P.; Sivanesan, S.; Bafana, A., Environ. Sci. Pollut. Res., 2019, 1-18.

2. Muniz-Miranda, M., Appl. Catal. B-Environ., 2014, 146, 147-150.

3. Gu, S.;Wunder, S.; Lu, Y.; Ballauff, M.; Fenger, R.; Rademann, K.; Jaquet, B.; Zaccone, A., Phys. Chem., C 2014, 118, 18618-18625.

4. Sudhakar, P.; Soni, H., J. Environ. Chem. Eng., 2018, 6, 28-36.

5. Rengga, W. D. P.; Chafidz, A.; Sudibandriyo, M.; Nasikin, M.; Abasaeed, A. E., J. Environ. Chem. Eng., 2017, 5, 1657-1665.

6. Altintig, E.; Arabaci, G.; Altundag, H., Surf. Coat. Technol., 2016, 304, 63-67.

7. Saran, S.; Manjari, G.; Devipriya, S. P., J. Clean. Prod., 2018, 177, 134-143.

8. Yan, Z.; Fu, L.; Zuo, X.; Yang, H., Appl Catal B-Environ., 2018, 226, 23-30.

9. Khrizanforov, M. N.; Fedorenko, S. V.; Mustafina, A. R.; Kholin, K. V.; Nizameev, I. R.; Strekalova, S. O.; Grinenko, V. V.; Gryaznova, T. V.; Zairov, R. R.; Mazzaro, R., Dalton Transactions., 2018, 47, 9608-9616.

10. Han, Y.; Wu, X.; Zhang, X.; Zhou, Z.; Lu, C., ACS Sustain. Chem. Eng., 2016, 4, 6322-6331.

11. Goswami, M.; Baruah, D.; Das, A. M., New J. Chem., 2018, 42, 10868-10878.

12. Dutta, P.; Wang, B., Coord. Chem. Rev., 2019,
383, 1-29.

13. Patra, S.; Naik, A. N.; Pandey, A. K.; Sen, D.; Mazumder, S.; Goswami, A., Appl. Catal. A-Gen., 2016, 524, 214-222.

14. Kamal, T.; Ahmad, I.; Khan, S. B.; Asiri, A. M., Carbohydr. Polym., 2017, 157, 294-302.

15. Ali, N.; Kamal, T.; Ul-Islam, M.; Khan, A.; Shah, S. J.; Zada, A., Int. J. Biol. Macromol., 2018, 111, 832-838.

16. Ma, Y.; Wang, H.; Ji, S.; Goh, J.; Feng, H.;Wang, R., Electrochim. Acta., 2014, 133, 391-398.

17. Shuihua, T.; Gongquan, S.; Jing, Q.; Shiguo, S.; Junsong, G.; Qin, X.; Haarberg, G. M., Chinese J Catal., 2010, 31, 12-17.

18. Xia, J.; He, G.; Zhang, L.; Sun, X.; Wang, X., Appl. Catal. B-Environ., 2016, 180, 408-415.

19. Qin, L.; Yi, H.; Zeng, G.; Lai, C.; Huang, D.; Xu, P.; Fu, Y.; He, J.; Li, B.; Zhang, C., J. Hazard. Mater., 2019, 380, 120864.

20. Kastner, C.; Thunemann, A. F., Langmuir., 2016, 32, 7383-7391.

21. Zook, J. M.; Long, S. E.; Cleveland, D.; Geronimo, C. L. A.; MacCuspie, R. I., Anal. Bioanal. Chem., 2011, 401, 1993.

22. Khodashenas, B.; Ghorbani, H. R., Arab. J. Chem., 2019, 12, 1823-1838.

23. Menumerov, E.; Hughes, R. A.; Neretina, S., Nano Lett., 2016, 16, 7791-7797. 